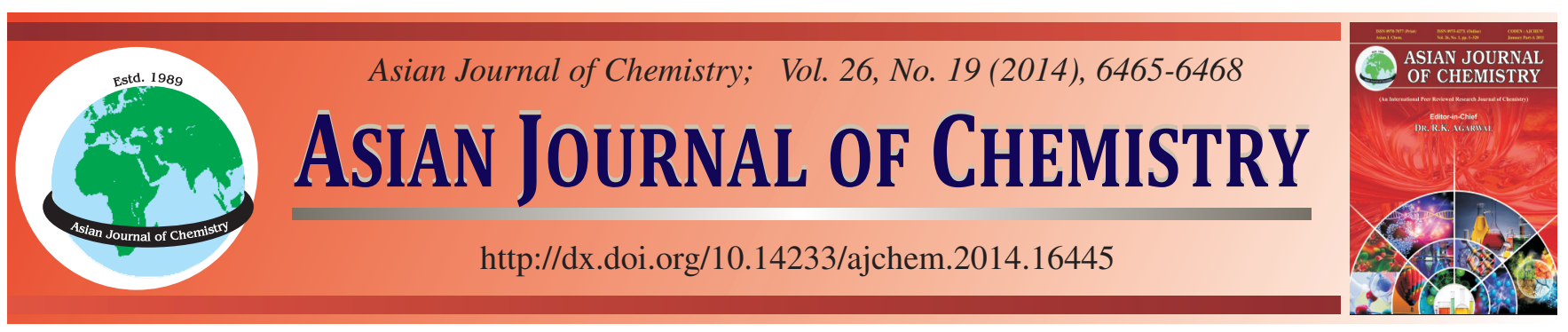

\title{
Development of Fast Reverse Phase Liquid Chromatographic Method for Simultaneous Analysis of Betamethasone Dipropionate and Calcipotriol in Ointments and Bulk Drug
}

\author{
Shankar L. Turwale, Rajesh K. Dwivedi and Madhusudan T. Bachute*
}

Department of chemistry, Karmveer Bhaurao Patil Mahavidyalay, Pandharpur-413 304, India

*Corresponding author: E-mail: mbachute@gmail.com

Received: 30 September 2013; $\quad$ Accepted: 17 February 2014; $\quad$ Published online: 16 September 2014; $\quad$ AJC-15941

\begin{abstract}
A simple, fast and cost effective reverse phase isocratic liquid chromatographic method has been developed for the simultaneous analysis of betamethasone dipropionate and calcipotriol in ointment and bulk drugs. Mixture of water and methanol in the ratio of 200:800 v/v was used as mobile phase. Separation of drugs was achieved using C-18, $150 \times 4.6 \mathrm{~mm}, 5 \mu$ column from Phenomenox Luna. Analyses were carried out using UV detector at $265 \mathrm{~nm}$ wavelength and flow rate was kept $1 \mathrm{~mL} / \mathrm{min}$. The retention times were about $4.5 \mathrm{~min}$ for betamethasone dipropionate and about $6.9 \mathrm{~min}$ for calcipotriol. Linearity shows correlation coefficient $\mathrm{r}^{2}=1$ for calcipotriol and $\mathrm{r}^{2}=0.999$ for betamethasone dipropionate. The percentage recovery for betamethasone dipropionate and calcipotriol was 98.6 and $99.5 \%$ respectively. Samples were subjected to alkali, acid, redox, thermal, humidity and photolytic degradation. Both the drugs were well separated from all degradants. Intra day $(n=6)$ and inter day precision $(n=12)$ gives RSD 0.67 and $0.63 \%$, respectively for betamethasone dipropionate and 1.14 and $0.88 \%$, respectively for calcipotriol. Method has been validated as per ICH guideline. Proposed method is simple and cost effective. Rapid separation of both the drugs is achieved within 7 min using simple mobile phase which makes this method simple, rapid and economic for routine simultaneous determination of calcipotriol and betamethasone dipropionate.
\end{abstract}

Keywords: Calcipotriol, Betamethasone dipropionate, Ointment formulations, HPLC, Validation, Method development.

\section{INTRODUCTION}

Calcipotriol also called as calcipotriene and is synthesized from vitamin $\mathrm{D}$ or calcitriol. It is used for the treatment of psoriasis, alopecia areata and androgenic alopecia ${ }^{1}$. Betamethasone dipropionate is a steroidal derivative showing immunosuppressive and antiinflammatory activities ${ }^{2}$. It is the matter of great concern that world's 1 to $3 \%$ population is affected by a common skin disease psoriasis. Therefore there is a wide scope for safe and effective therapeutic options. Combination therapy of calcipotriol and betamethasone dipropionate offers a better option for maintenance therapy to psoriatic patients. Structures of calcipotriol and Betamethasone dipropionate are shown in Fig. $1 \mathrm{a}$ and $1 \mathrm{~b}$, respectively.

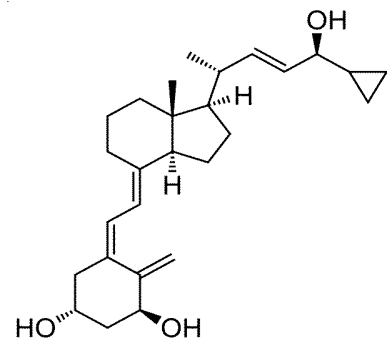

Fig. 1a. Structure of calcipotriol

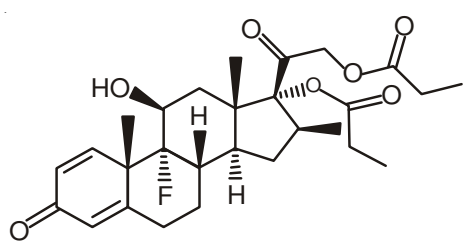

Fig. 1b. Structure of betamethasone dipropionate

Topical pharmaceutical preparations i.e. creams, ointments, lotions, foams, gels etc. are generally used to treat skin deseases. Now day's pharmaceutical industries are showing increasing interest in topical preparations by using combination of drug molecules for simultaneous mechanism of action. Simultaneously, for accurate analysis of any pharmaceutical dosage form, simple, rapid and reproducible analytical methods are required. Liquid chromatographic separation technique is most preferable analytical technique used in pharmaceutical industries to separate and quantify the drug molecules.

Literature survey revealed that there are some methods reported for individual determination of calcipotriol and for betamethasone in cream samples ${ }^{3-8}$. There are only three methods reported $^{9-11}$ on simultaneous determination of calcipotriol and betamethasone dipropionate in ointment topical formulations. Simonsen et al. ${ }^{9}$ reported a method for simultaneous determination 
of betamethasone dipropionate and calcipotriol, in which the reported retention time for calcipotriol is longer (12 $\mathrm{min})$ and accuracy of calcipotriol is only $92 \%$.

Yan et al. ${ }^{10}$ used a three component mobile phase comprising a mixture of acetonitrile, methanol and phosphate buffer adjusted to $\mathrm{pH} 6$ to achieve the separation of both drugs. In this method use of highly toxic and costly solvent acetonitrile is made. Singh et al $^{11}$ reported a method for simultaneous determination of betamethasone dipropionate and calcipotriol. In this method long retention times reported for calcipotriol and betamethasone dipropionate are 7.99 minute and 13.99 min, respectively. These reports tempted us to develop an accurate, simple, rapid and cost effective analytical method for simultaneous analysis of betamethasone dipropionate and calcipotriol.

In proposed method simple isocratic mobile phase [water: methanol, 20:80 (v/v)] is used to achieve the separation of both the drugs. It is note worthy that the retention time for both drugs is very short. It is $4.5 \mathrm{~min}$ for betamethasone dipropionate and $6.9 \mathrm{~min}$ for calcipotriol which help to save time and consumption of solvents. Further, this method gives $99.5 \%$ accuracy for calcipotriol and $98.6 \%$ for betamethasone. The most notable thing is that in this method the use of highly toxic and costly acetonitrile is completely avoided. Method has been validated as per ICH guideline ${ }^{12,13}$. Therefore, the method is more accurate, simple, rapid and cost effective in comparison with the reported methods.

\section{EXPERIMENTAL}

Betamethasone dipropionate, calcipotriol and ointment were provided by Glenmark Generics Limited. Milli Q grade Water and HPLC grade methanol was used. Shimadzu 2010 HPLC equipped with Auto sampler, ultraviolet and photo diode array detector was used.

Chromatographic conditions: Mixture of methanol and water in ratio of $8: 2 \mathrm{v} / \mathrm{v}$ was used as mobile phase at a flow rate of $1 \mathrm{~mL} / \mathrm{min}$, column oven temperature was kept at $25^{\circ} \mathrm{C}$ and eluents were monitored at detection wavelength of 265 $\mathrm{nm}$. Phenomenox Luna C18 $150 \times 4.6 \mathrm{~mm}, 5 \mu$ particle size column was used. $50 \mu \mathrm{L}$ was the injection volume. Using these analytical conditions, betamethasone dipropionate eluted at about $4.5 \mathrm{~min}$ and calcipotriol at about $6.9 \mathrm{~min}$.

Preparation of diluents: $0.01 \mathrm{M}$ ammonium dihydrogen phosphate was adjusted to $\mathrm{pH} 6.2$ using triethylamine. 2 volumes of this buffer was mixed with 8 volumes of methanol and used as diluents

Preparation of standard solutions: Stock (A): Accurately weighed about $26 \mathrm{mg}$ of betamethasone dipropionate standard was taken in a volumetric flask of $100 \mathrm{~mL}$ capacity and was dissolved in $75 \mathrm{~mL}$ diluents by sonication. After sonication volume was made up to mark with diluents. Stock (B): Accurately weighed about $10 \mathrm{mg}$ of calcipotriol standard was taken in a $200 \mathrm{~mL}$ volumetric flask and was dissolved in about 135 $\mathrm{mL}$ diluents by sonication. Volume was made up to mark with diluents.

Preparation of final standard solution: Diluted $5 \mathrm{~mL}$ of standard Stock (A) and $2 \mathrm{~mL}$ of standard Stock (B) to 100 $\mathrm{mL}$ with mobile phase.
Preparation of sample solution: Ointment sample equivalent to about $13 \mu \mathrm{g} / \mathrm{mL}$ of betamethasone dipropionate and about $1 \mu \mathrm{g} / \mathrm{mL}$ of calcipotriol was weighed in $50 \mathrm{~mL}$ volumetric flask. $5 \mathrm{~mL}$ tetrahydrofuran was added and mixture was kept at $60{ }^{\circ} \mathrm{C}$ on water bath to disperse entire sample in tetrahydrofuran. $30 \mathrm{~mL}$ diluent was added and mixture was further kept on water bath for $5 \mathrm{~min}$. Mixture was cooled to room temperature and was made up to mark with diluents. Solution was filtered through $0.45 \mu \mathrm{m}$ Teflon syringe filter.

Typical chromatogram of standard solution is shown in Fig. 2.

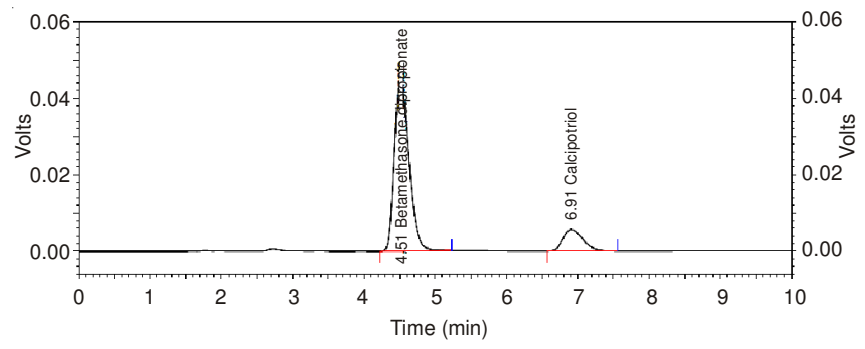

Fig. 2. Typical chromatogram of standard solution

\section{RESULTS AND DISCUSSION}

A satisfactory separation between betamethasone dipropionate and calcipotriol with good peak resolution and symmetry was achieved with mixture of methanol and water in the ratio of 80:20 (v/v) as mobile phase. The proposed method gives good peak shapes of betamethasone dipropionate and calcipotriol and well separated from each other and from degradants also. Method validation of proposed method was performed as per ICH guideline. To ensure suitability and authenticity of method, validation parameters viz., specificity, linearity, accuracy and precision, robustness and solution stability were evaluated. Results of this study show that method is simple, rapid and cost effective.

Specificity: Specificity was performed by evaluating any potential co-elution of either blank or placebo at the elution time of betamethasone dipropionate and calcipotriol peaks. Identification of betamethasone dipropionate and calcipotriol peaks was established by comparison of elution time of standard solution of both drugs. Both the peaks were evaluated for peak purity using photo diode array detector (PDA).

It was observed that there was no interference from placebo and blank at the elution time of betamethasone dipropionate and calcipotriol peaks. Elution time of betamethasone dipropionate and calcipotriol peaks in sample solution matched the elution time of individual peaks in standard solution. Peak purity of betamethasone dipropionate and calcipotriol was satisfactory. These results indicate that proposed method gives uniform and pure peaks of betamethasone dipropionate and calcipotriol.

Forced degradation studies: Forced degradation studies were done by subjecting samples to alkali degradation $(2 \mathrm{~N}$ $\mathrm{NaOH}, 0 \mathrm{~h}$ and $24 \mathrm{~h}$ ), ccid degradation( $5 \mathrm{~N} \mathrm{HCl}, 0 \mathrm{~h}$ and $24 \mathrm{~h}$ ), peroxide $\left(30 \% \mathrm{H}_{2} \mathrm{O}_{2}, 0 \mathrm{~h}\right.$ and $\left.24 \mathrm{~h}\right)$, thermal $\left(90{ }^{\circ} \mathrm{C}\right.$ for $\left.72{ }^{\circ} \mathrm{C}\right)$, photolytic 1.2 million lux hours $)$ and humidity $\left(25^{\circ} \mathrm{C} /\right.$ $90 \%$ relative humidity for $72 \mathrm{~h}$ ). 
It was observed that betamethasone dipropionate and calcipotriol were well separated from degradants in all stress conditions. Uniformity of peaks of betamethasone dipropionate and calcipotriol in degraded samples was confirmed by checking peak purity using PDA detector. In all degraded samples peak purity passes for betamethasone dipropionate and calcipotriol implies stability indicating potential of proposed method.

Linearity: Linearity was established with 7 different solutions of varying concentrations. Seven dilutions were made in such a way that final concentrations of betamethasone dipropionate was in the range of 6.50 to $19.5 \mu \mathrm{g} / \mathrm{mL}$ and 0.5 to $1.5 \mu \mathrm{g} / \mathrm{mL}$ for calcipotriol. A calibration curve was plotted between area response and concentration. Linearity data and curve is shown in Table-1 and Fig. 3a, respectively for betamethasone dipropionate.

TABLE-1

\section{LINEARITY DATA FOR BETAMETHASONE DIPROPIONATE}

\begin{tabular}{ccccc}
\hline Sr. No. & $\begin{array}{c}\text { Linearity } \\
\text { level }\end{array}$ & $\begin{array}{c}\text { Concentration } \\
(\mu \mathrm{g} / \mathrm{mL})\end{array}$ & $\begin{array}{c}\text { Area response } \\
(\mathrm{mAU})\end{array}$ & $\begin{array}{c}\text { Correlation } \\
\text { coefficient }\left(\mathrm{r}^{2}\right)\end{array}$ \\
\hline 1 & Lin-1 & 6.50 & 320297 & \\
2 & Lin-2 & 10.40 & 511391 & \\
3 & Lin-3 & 11.70 & 578210 & \\
4 & Lin-4 & 13.01 & 643812 & 0.999 \\
5 & Lin-5 & 14.31 & 705974 & \\
6 & Lin-6 & 15.61 & 773965 & \\
7 & Lin-7 & 19.51 & 969788 & \\
\hline
\end{tabular}

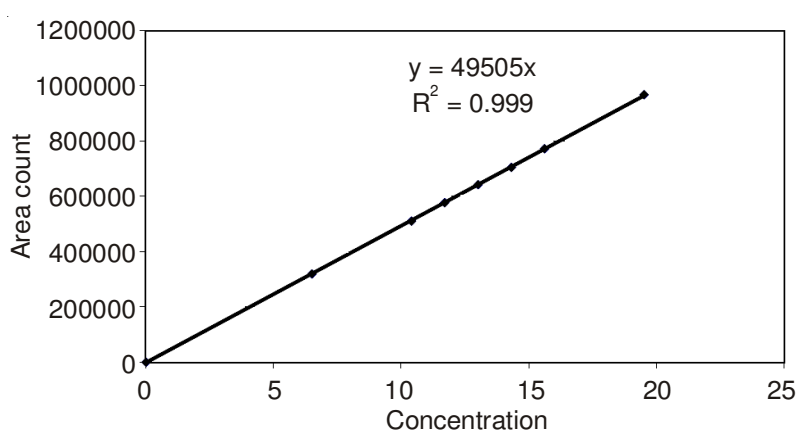

Fig. 3a. Linearity curve for betamethasone dipropionate

Linearity data and curve for calcipotriol is shown in Table-2 and Fig 3b, respectively.

Accuracy: Accuracy of method was demonstrated by checking recovery of betamethasone dipropionate and calciporiol using standard addition method. As per this method a known amount of betamethasone dipropionate and calciporiol was spiked to placebo in three different levels $(80$, 100 and $120 \%$ of sample concentration) and prepared three spiked samples of each level. These spiked samples were analyzed against working standard and the amount of betamethasone dipropionate and calciporiol recovered in three different levels was calculated.
TABLE-2

\section{LINEARITY DATA FOR CALCIPOTRIOL}

\begin{tabular}{ccccc} 
Sr.No. & $\begin{array}{c}\text { Linearity } \\
\text { level }\end{array}$ & $\begin{array}{c}\text { Concentration } \\
(\mu \mathrm{g} / \mathrm{mL})\end{array}$ & $\begin{array}{c}\text { Area response } \\
(\mathrm{mAU})\end{array}$ & $\begin{array}{c}\text { Correlation } \\
\text { coefficient }\left(\mathrm{r}^{2}\right)\end{array}$ \\
\hline 1 & Lin-1 & 0.50 & 55179 & \\
2 & Lin-2 & 0.80 & 88848 & \\
3 & Lin-3 & 0.90 & 100009 & \\
4 & Lin-4 & 1.00 & 111017 & 1.000 \\
5 & Lin-5 & 1.10 & 121985 & \\
6 & Lin-6 & 1.20 & 132979 & \\
7 & Lin-7 & 1.50 & 165784 & \\
\hline
\end{tabular}

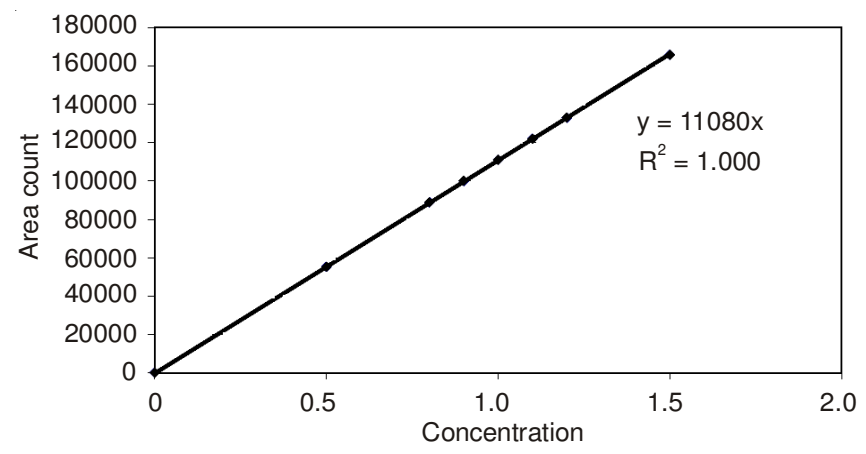

Fig. 3b. Linearity curve for calcipotriol

Recovery for betamethasone dipropionate was 98.6 and $99.5 \%$ for calcipotriol. Results of recovery experiment are shown in Table-3.

Method precision: Precision or repeatability of the method was demonstrated by analyzing six different sample preparations of same lot. Assay of betamethasone dipropionate and calciporiol was estimated for all these six sample solutions. Relative standard deviation was calculated for assay results of betamethasone dipropionate as well as calcipotriol.

Relative standard deviation was $0.67 \%$ for betamethasone dipropionate and 1.14 for calcipotriol. These values demonstrated precision and repeatability of proposed method.

Results of method precision or repeatability are shown in Table-4.

Ruggedness: Reproducibility was demonstrated by relative standard deviation of assay results for 12 samples preparations. For this purpose 6 fresh preparations were made and 6 preparations of precision experiment were used. Assay values of all the six samples were calculated. RSD of six samples were calculated and also checked for cumulative RSD with six assay values of method precision. Relative standard deviation of assay of cumulative 12 samples (reproducibity and precision experiment) was $0.63 \%$ and 0.88 , respectively for betamethasone and calcipotriol. The assay results and relative standard deviation values demonstrated reproducibility of proposed method.

TABLE-3

RECOVERY RESULTS OF BETAMETHASONE DIPROPIONATE AND CALCIPOTRIOL

\begin{tabular}{cccc|cc}
\hline S. & Accuracy & \multicolumn{2}{c}{ Betamethasone dipropionate } & \multicolumn{2}{c}{ Calcipotriol } \\
\cline { 3 - 6 } No. & level (\%) & \% Recovery (Mean of 3 samples) & \% Mean recovery & \% Recovery (Mean of 3 samples) & \% Mean recovery \\
\hline 1 & Accuracy-80 & 98.8 & 98.6 & 99.5 & \\
2 & Accuracy-100 & 98.6 & 99.5 & 99.5 \\
3 & Accuracy-120 & 98.3 & 99.5 & \\
\hline
\end{tabular}


TABLE-4

REPEATABILITY RESULTS OF BETAMETHASONE DIPROPIONATE AND CALCIPOTRIOL

\begin{tabular}{|c|c|c|c|c|c|}
\hline \multirow{2}{*}{ Sr.No. } & \multirow[t]{2}{*}{ Sample preparations } & \multicolumn{2}{|c|}{ Betamethasone dipropionate } & \multicolumn{2}{|c|}{ Calcipotriol } \\
\hline & & \% Assay Value & $\%$ RSD & \% Assay Value & $\%$ RSD \\
\hline 1 & Preparation-1 & 99.38 & & 100.83 & \\
\hline 2 & Preparation-2 & 98.70 & & 100.33 & \\
\hline 3 & Preparation-3 & 98.27 & 067 & 98.04 & \\
\hline 4 & Preparation-4 & 99.43 & $0.6 /$ & 99.68 & 1.14 \\
\hline 5 & Preparation-5 & 99.92 & & 98.88 & \\
\hline 6 & Preparation-6 & 99.92 & & 100.87 & \\
\hline
\end{tabular}

Robustness: Robustness was evaluated by changing some chromatographic conditions e.g. mobile phase ratio, flow rate and column temperature. Changes were varied by $\pm 5 \%$ for mobile phase composition and flow rate while temperature was changed by $\pm 2{ }^{\circ} \mathrm{C}$. Two different lots of same make column were also used for this purpose. Altering these method parameters to small degree, no significant effect was observed on the results. Less than $2 \%$ difference was observed in assay value of altered condition and mean assay value of precision experiment. Relative standard deviation of peak area response and elution time was less than $1 \%$. These values demonstrated robustness of proposed method.

Filter compatibility: Filter compatibility was demonstrated by dividing sample solution in two parts. One part of solution was centrifuged and other part was filtered using 0.45 $\mu \mathrm{m}$ filters. Filters used for this experiment were PTFE, Teflon and PVDFs. Results obtained by filtering and centrifuging the samples was compared. Absolute difference between results for filtered solutions and centrifuged solutions was not more than $1.5 \%$. It was demonstrated that there is no adsorption of either of the drug substance on filter papers during filtration.

Solution stability: It is vital for any chromatographic method that test solution used during analysis should be reasonably stable. Stability of a solution was demonstrated by comparing assay value of initially prepared sample with same solution kept for a period of $24 \mathrm{~h}$ at room temperature. Solutions of standard and test preparations were initially analyzed and assay of test preparation was calculated. Solutions of standard and test preparations were allowed to remain overnight $(24 \mathrm{~h})$ at room temperature. Next day a fresh standard preparation was made and the stored sample was analyzed using fresh standard preparation. Assay results of initial sample and stored sample (for $24 \mathrm{~h}$ at room temperature) were compared. Variation between assay of fresh prepared sample solution and stored sample solution was less than $1.5 \%$. This demonstrated solution stability up to $24 \mathrm{~h}$.

\section{Conclusion}

Proposed method is simple, accurate, cost effective and user friendly. Method validation parameters meet the specifications laid down in ICH guidelines. This method is advantageous over reported methods and is capable of improving efficiency and output of an analytical laboratory. This can be easily and suitably applied for day to day analysis of betamethasone dipropionate and calcipotriol from topical ointment pharmaceutical formulations.

\section{ACKNOWLEDGEMENTS}

Thanks to Department of Chemistry, Karmveer Bhaurao Patil Mahavidyalay, Pandharpur, India for consistent support to complete this work.

\section{REFERENCES}

1. http://en.wikipedia.org/wiki/Calcipotriol.

2. http://en.wikipedia.org/wiki/Betamethasone_dipropionate.

3. M. Singh, R.M. Charde and M.S. Charde, J. Pharmacy Res., 4, 845 (2011).

4. J.J.N. Cirunay, Y. Vander Heyden and J. Plaizier-Vercammen, J. Chromatogr. Sci., 36, 417 (1998).

5. A. Santos-Montes, A.I. Gasco-Lopez and R. Izquierdo-Hornillos, Chromatographia, 39, 539 (1994).

6. R. Ankam, K. Mukkanti, S. Durgaprasad and M. Khan, Indian J. Pharm. Sci., 71, 547 (2009).

7. S.E. Johnston, N.L. Gill, Y.-C. Wei, R. Markovich and A.M. Rustum, J. Chromatogr. Sci., 48, 733 (2010).

8. S.D. Bhosale and S.J. Rajput, J. AOAC Int., 94, 106 (2011).

9. L. Simonsen, G. Høy, E. Didriksen, J. Persson, N. Melchior and J. Hansen, Drug Develop. Ind. Pharm., 30, 1095 (2004).

10. S. Yan, D.-X. Chen and Z.-G. He, China Pharmacy, 21, 1996 (2011).

11. M. Singh, M.S. Charde and R.M. Charde, Asian J. Res. Chem., 4, 602 (2011).

12. I.C.H. Harmonised Tripartite Guideline, International Conference on Harmonization of Technical Requirements for Registration of Pharmaceuticals for Human Use, Validation of Analytical Procedure: Methodology (1996).

13. L.R. Snyder, J.J. Kirkland and J.L. Glajch, Practical HPLC Method Development, Wiley-Interscience, New York (1977). 